\title{
(Re)configuração curricular no processo de formação de professores e suas relações
}

Curricular area of construction in the process of teacher education and relations

Liliane Campos Machado* Universidade de Brasília

Resumo Esse artigo resulta de uma investigação cujo objeto de pesquisa é o currículo e a formação de professores. Enfocamos algumas reflexões sobre um currículo para a formação de professores por acreditarmos que esta é um espaço para a construção curricular. A questão norteadora desse trabalho de pesquisa foi "Como o processo de formação de professores e suas relações produzem determinadas configurações de currículos?”. Objetivamos com esse estudo investigar a formação de professores, inclusive ou também como um espaço de construção curricular. Privilegiou-se a abordagem qualitativa na perspectiva histórico-cultural. $\mathrm{O}$ estudo evidenciou que o desenvolvimento curricular está diretamente relacionado ao desenvolvimento da formação do professor no que se refere aos saberes e às práticas.

PALAVRAS-CHAVE: Formação de professores; Profissão e profissionalidade; Currículo.

Abstract This article results from a research whose object of study is the curriculum and teacher training. We highlight some reflections about a curriculum for teacher education because we believe that this is a space for curriculum construction. The guiding question of this research was "How the process of teacher education and their relationships produce certain configurations of resumes?". This study we aimed to investigate the teacher education as an area of curriculum construction. We focused on the qualitative approach in historical and cultural perspective. The study showed that curriculum development is directly related to the development of teacher training in relation to knowledge and practices.

KEYWORDS: Teacher education; Profession and professionalism; Résumé. 


\section{Introdução}

Quando a educação acontece, provoca transformação. Esta estabelece relações com: o conhecimento, a análise crítica, a participação na sociedade, a política e a economia. Daí a importância de se discutir a (re)configuração curricular no contexto da formação de professores.

Segundo Apple (2003) as rápidas transformações que ocorrem no mundo atual e, sobretudo, o processo de globalização que envolve as esferas econômica, política e social têm provocado repercussões variadas em diversas nações do globo, bem como nos diferentes grupos sociais que integram vários países. Se no plano econômico a globalização vem integrando mercados, cuja consequência é o aumento do poder de algumas nações, no plano social agravam problemas como o desemprego, as distorções na distribuição de renda no interior dos países globalizados e também entre diferentes países não globalizados.

A globalização impõe algumas alterações no campo de trabalho docente, por isso, é preciso situá-las no interior das transformações no contexto social e, especificamente, no contexto educacional.

Nessa perspectiva, ao discutir sobre o currículo e suas configurações, refletimos sobre a necessidade de articulação entre a ação do docente e o desenvolvimento curricular. Vale registrar que a partir da promulgação da Lei de Diretrizes e Bases da Educação Nacional, em 1996, foi editado um conjunto de regulamentações relacionadas à formação inicial de professores; dentre elas, a elaboração de diretrizes curriculares nacionais para os cursos de formação de professores. Notamos com isso que as ações apontadas nas diretrizes incluem, dentre outros aspectos, a valorização do componente da "prática educativa", o desenvolvimento de competências e o aproveitamento da experiência docente.

Neste artigo, fazemos uma breve incursão no campo das políticas educacionais contemporâneas, tendo como ponto central a análise de suas repercussões na formação e no trabalho docente. $\mathrm{Na}$ sequência propomos uma discussão sobre um currículo para a formação docente, na sociedade do conhecimento e da informação, explorando aspectos da nova arquitetura que configuram sistemas de ensino, na qual se desenvolve uma nova atmosfera de trabalho, a da cultura do desempenho, que configura e/ou reconfigura as formas de trabalho, as relações dos docentes e a construção curricular.

\section{Formação de Professores: contexto legal}

Tanto as reformas educacionais quanto à formação docente são consideradas fatores estratégicos, no processo de desenvolvimento do capitalismo. Observamos que a educação tem sido objeto de discussões, de programas e de projetos levados a cabo por órgãos multilaterais de financiamento, como as agências do Banco Mundial (BID e BIRD), e por órgãos voltados para a cooperação técnica como o UNICEF e a UNESCO (CURY, 2002). Esses organismos orientam financiam e definem diretrizes 
que norteiam políticas e projetos educacionais em diferentes partes do mundo, inclusive no Brasil.

Assim sendo, torna-se importante observar, por um lado, a participação de tais organismos nas políticas educacionais brasileiras, destacando o papel exercido pelo Banco Mundial, em diferentes esferas do campo educacional. Segundo (TORRES, 1996), dentre os critérios que fundamentam as orientações do Banco Mundial para a educação destacam-se: a elaboração de currículos sintonizados com as demandas do mercado ${ }^{1}$; centralidade para a educação básica, com a redução de gastos com a educação superior; ênfase na avaliação do ensino em termos dos produtos da aprendizagem e do valor custo/benefício; centralidade da formação docente em serviço em detrimento da formação inicial; autonomia das escolas com o maior envolvimento das famílias; desenvolvimento de políticas compensatórias voltadas para os portadores de necessidades especiais e para as minorias culturais.

Por outro lado, de maneira generalizada, podemos dizer que, no processo de redemocratização do Brasil, intensificou-se a preocupação com a melhoria da educação, não apenas em termos de atendimento à demanda escolar, mas, sobretudo, visando o regresso dos evadidos, a permanência e o sucesso dos alunos nas escolas, bem como a melhoria do ensino. Neste quadro observamos que, em consonância com as reivindicações dos movimentos sociais, abre-se espaço para o desenvolvimento de movimentos de renovação pedagógica, orientados por propostas da chamada "pedagogia crítica". Tais movimentos advogam: a) a instauração de processos participativos, por meio dos sindicatos e Conselhos das categorias profissionais, da inserção da comunidade escolar na administração das unidades de ensino; b) a criação de novas formas de organização do ensino, com a introdução no âmbito do currículo de novos conteúdos e de novas práticas pedagógicas, com ênfase na integração dos conteúdos curriculares; c) uma nova visão da profissão docente ${ }^{2}$, que, além de ampliar os níveis de participação e de decisões do profissional da educação, propõe que este deva orientar seu trabalho por uma reflexão crítica sobre sua prática e por compromissos éticos relacionados à superação dos mecanismos intra-escolares responsáveis pela exclusão dos estudantes das camadas populares (WHITTY \& POWER, 2003; PACHECO, 2002; TARDIF, 2000).

A formação de professores, bem como a própria educação, significam um desafio constante, como demonstra a própria história da educação. No Brasil, encontramos uma maior preocupação com a formação dos professores além das primeiras quatro séries somente a partir dos anos 30 do século $\mathrm{XX}$, no contexto da reforma de Francisco Campos. Naquele momento histórico, o modelo adotado era o famoso $3+$ 1 , onde o futuro professor se formava primeiramente como bacharel de uma determinada disciplina, para depois cursar a Didática como um curso independente (VEIGA, 1996). Este modelo sofreu durante o século XX uma série de alterações, mas a tendência de ter como fundamento uma ampla formação na área específica e concentrar as disciplinas pedagógicas no final do curso encontra-se, ainda hoje, em muitos currículos de licenciatura. 
Neste sentido, a nova Lei de Diretrizes e Bases da Educação, de 1996, determina que a formação de profissionais da educação básica far-se-á em nível superior em cursos de licenciatura, de graduação plena (Art. 62). Em relação a estes cursos, a Resolução do Conselho Nacional de Educação, CNE/CP 2/2015 que define as diretrizes curriculares nacionais para a formação inicial em nível superior compreende currículo como "o conjunto de valores e práticas que proporcionam a produção, a socialização de significados no espaço social e contribuem para a construção de identidades socioculturais dos educandos ao difundir valores fundamentais do interesse social, dos direitos e deveres dos cidadãos, do respeito ao bem comum e à democracia, articulados à orientação para o trabalho e promoção de práticas educativas formais e não-formais" (RESOLUÇÃO, 02/2015, p. 2).

No que se refere à docência o referido documento a evidencia como "ação educativa e como processo pedagógico intencional e metódico, envolvendo conceitos, princípios e objetivos da licenciatura que se desenvolvem entre conhecimentos científicos e culturais, nos valores éticos e estéticos inerentes ao ensinar e aprender, na socialização e construção de conhecimentos, diálogo constante entre diferentes visões de mundo e sua inovação" (RESOLUÇÃO, 02/2015, p. 2). Esse conceito é reiterado no Art. $2^{\circ}$ no $\S 1^{\circ}$ da referida resolução.

Para além dessa concepção de docência apresentada na p. 2 e no $§ 1^{\circ}$ do Art $2^{\circ}$, o texto traz também uma concepção de docência ampliada, que pode ser compreendida com base no Art. 13: quando diz que: os cursos de formação inicial, em cursos de licenciatura plena, podem ser organizados em áreas especializadas, por componente curricular ou por campo de conhecimento, considerando-se a complexidade e multirreferencialidade dos estudos que os englobam, bem como a formação para o exercício integrado e indissociável da docência na educação básica, da gestão dos processos educativos escolares e não-escolares, da produção e difusão do conhecimento científico, tecnológico e educacional estruturando-se por meio da garantia da base comum nacional e das orientações curriculares (RESOLUÇÃO, 2/2015. p. 11).

Nessa perspectiva, a docência como base da formação garante também uma formação unificada, pois a capacitação para a docência pressupõe capacitação para outras funções técnicas educacionais, considerando que a docência é a mediação para outras funções que envolvem o ato educativo intencional. A resolução esclarece que o professor, após concluir o curso superior, não será mais visto como um bacharel com algum conhecimento para atuar na área de educação, mas sim como profissional com perfil de educador competente e que atende as exigências legais para atuar.

A exigência de cursos com perfis próprios para as licenciaturas, em conjunto com as obrigações de carga horária definida pela da Resolução CNE/CP 2/2015, e com a necessidade de adequação dos currículos significa um desafio pois exige mudanças. Por outro lado, a necessidade de modificações do currículo oferece aos formadores uma oportunidade de repensarem a formação de professores.

Portanto, faz-se necessário uma ampla discussão dessas Diretrizes para que a partir da compreensão da proposta de formação expressa em seus códigos tanto ex- 
plícitos quanto implícitos possa construir currículos que atendam não só às exigências legais, mas também às demandas por uma formação que atenda todas as classes sociais, no intuito de colaborar com o processo de discussão. Procede-se aqui uma análise ainda inicial, tomando por base as resoluções CNE/CP 01, de 18 de Fevereiro de 2002, e a CNE/CP 02, de 01 de julho de 2015 que respectivamente instituem as diretrizes e a carga horária dos cursos de formação de professores para a educação básica em nível superior.

\section{Formação de Professores: profissão e profissionalidade do- cente}

Iniciamos esse tópico do artigo, recorrendo a Veiga (2005, p. 25) para conceituar o termo profissão, esse tem sua origem no latim "professio" significando: declaração, profissão, exercício, emprego. O termo evoluiu socialmente e "está marcado por mudanças sociais e econômicas ocorridas ao longo da história. A profissão é um ato específico e complexo e diz respeito a um grupo especializado, competente". Assim sendo, a autora afirma que um grupo profissional se constitui por pessoas que se unem por uma identidade e por éticas comuns. (VEIGA, et.al, 2005, p. 25).

No que se refere à profissionalização, Veiga (2008) afirma que ela é um processo de aquisição das capacidades específicas da profissão, uma vez que não se resume à formação profissional, embora também esteja incluída, a profissionalização comporta também características de cunho subjetivo, como aptidões, atitudes, valores, formas de trabalho, que se vão constituindo no exercício da profissão.

Concebemos nesse trabalho de pesquisa a formação como um fazer que se desenvolve em um contexto de coletividade. Veiga (2008) entende a formação como [...] posição de "inacabamento", vinculada à história de vida dos sujeitos em permanente processo de formação, que proporciona a preparação profissional. O processo de formação é multifacetado, plural, tem início e nunca tem fim. É inconcluso e auto formativo (2008: 15).

Pacheco, (2003), afirma que ser professor é viver na complexidade, no desafio permanente da melhoria, na multidimensionalidade do agir e pensar, na interrogação constante que a sociedade do conhecimento lhe coloca. É na sociedade do conhecimento e da informação que nascem novos desafios para a construção da profissionalidade docente (HARGREAVES, 2004), progressivamente pautada por critérios que de modo algum podem ignorar o humano e o profissional.

Corroborando as afirmações dos autores compreendemos que na construção de um novo profissionalismo, através de uma auto-crítica de aprendizagem, os professores são os catalisadores da sociedade do conhecimento, tornando-se vital que "se envolvam em conjunto na ação, no questionamento e na resolução de problemas, em equipes colegiais ou em comunidades de aprendizagem profissional" (HARGREAVES, 2004, p. 48).

Longe da utilidade e instrumentalidade da noção de competência (DIAS e LOPES, 2003), sobretudo quando associada ao centralismo administrativo, à buro- 
cracia escolar e à eficiência dos resultados, a formação docente ocorre numa sociedade onde "o conhecimento é um recurso flexível, fluido, sempre em expansão e em mudança" (HARGREAVES, 2004, p. 34), não sendo necessário falar da escola como um espaço de compra e venda de bens de consumo, mas como uma comunidade crítica de aprendizagem (YOUNG, 1998).

A ênfase da educação em geral, e particularmente da formação docente, está, por isso, na centralidade do conhecimento, com a clara tendência para o reforço de políticas mais eficientes, ainda que nominalmente designadas por políticas descentralizadas, de controle curricular, na mistificação da aprendizagem ao longo da vida.

Quando se discute a formação docente, em função da escola que temos, não se deixa de questionar o que significa ser professor em tempos marcados pela transitoriedade dos discursos e pela desconstrução de uma imagem social de escola, sobretudo a partir do momento que se deslegitima a educação como um direito cultural e passa a ser promovida como um produto de mercado. Nesta lógica de competição, a escola é a alavanca para se entrar numa economia do conhecimento competitiva e dinâmica, tornando o magistério uma profissão que requer maior controle técnico.

Assim, o principal desafio que a sociedade do conhecimento coloca em pauta não é o de seguir a uniformidade da formação docente, a estandardização de competências, mas o de problematizar o docente como pessoa, que luta continuamente pela construção de uma profissionalidade deliberativa, libertando-o dos propósitos das seitas da formação para o desempenho (HARGREAVES, 2004, p. 236), unicamente voltadas para o lado cognitivo da aprendizagem. Ser professor é admitir que há novos modos de olhar para a riqueza que existe no interior das escolas. Percorrer este caminho é uma luta que professores e formadores têm de travar, sabendo que a profissionalidade docente é algo que nos compromete com a qualidade dos processos de aprendizagem dos alunos.

Esse difícil processo de construção da profissionalidade docente, com idéias antagônicas, tanto em nível das escolas, quanto em nível das administrações educativas, debate-se o ser professor no palco da burocracia das tarefas e da sua "funcionalização", como se fosse uma atividade susceptível de aparecer num "guia eficiente de formar professores".

De modo a contrariar esta visão profissionalizante do docente, diremos que o docente tem que ser formado a partir de uma base epistêmica comum (JACKSON, 1968), ou de um conhecimento básico de ensino (SHULMAN, 1987). Reconhecerse-á, de igual modo, que a instituição de ensino superior assuma um papel cada vez mais central nesse processo. Todavia, tal natureza exige a consideração da escola como um dos contextos de formação, na medida em que existem saberes, cujo processo aquisitivo se processa a partir de uma prática pedagógica real.

Hargreaves (2004) afirma que a sociedade do conhecimento processa informação de forma a maximizar a aprendizagem, estimular a criatividade e a inventividade, desenvolver a capacidade de desencadear as transformações e enfrentá-las. 
Neste caso, o processo formativo do professor encontra, na prática profissional, não só o contexto de consolidação de uma identidade própria, mas neste, eles definem e estruturam o seu mundo de crenças a partir do contacto com a realidade escolar (PACHECO, 1995), mas também o campo permanente de (re)construção da sua profissionalidade. É por isso que na formação de um professor se registra um processo metacognitivo, isto é, um processo de articulação da teoria com a prática em que a atividade de conhecimento se torna objeto de reflexão (DOLY, 1999). Tornando-se possível, a partir da construção de um currículo específico para a formação de professores.

\section{Um currículo para a formação de professores: algumas re- flexões}

O desenho de um currículo para o ensino não é de forma alguma recente como sabemos. A "metodização" do conhecimento, seguindo uma determinada ordem taxonômica e hierárquica, do geral ao particular, numa "linear unbroken progression", em que as fronteiras de cada território se encontram claramente definidas num "logical map of knowledge", é normalmente atribuída ao Calvinista Peter Ramus (1516-1572).

Esta referência espaço-temporais não aparece aqui por acaso. Tem a ver com um quadro de rompimento com o passado, com raízes na Renascença, alicerçada pela Reforma e mais tarde assumida como projeto social pela Revolução Francesa. Rompimento este a que se assiste com maior acuidade ao longo da transição do século XIX para o século XX, suportado numa crença absoluta na ciência e na tecnologia, como meios de resolução dos problemas sociais ou naturais que assolavam a humanidade. Falamos, naturalmente, da emergência da sociedade moderna em ruptura com a tradição medieval dogmática e religiosa, a partir da defesa de uma ciência racional, de uma racionalidade "na ausência de toda a metafísica" (WEBER, 1968).

Ora, tanto a escola pública, surgida no auge da Revolução Industrial, com o currículo tecnológico que a enforma, na lógica de uma gestão científica do ensino que passa a ser conhecida como Rationale Tyler (a partir dos trabalhos de R. Tyler), são produtos dessa modernidade. Mas num contexto onde já soam sinais de pós-modernidade, como é o que atualmente vivemos, e de que as tecnologias de informação e comunicação são paradigmáticas, a questão que se nos coloca tem a ver com o papel que tanto a escola, como o currículo territorializado, podem protagonizar.

Sabemos, no entanto, que falar de modernidade e pós-modernidade não é tão consensual, como pode parecer à primeira vista. Saber se já estamos ou não vivendo a pós-modernidade depende do posicionamento que assumimos relativamente à própria modernidade. Como afirma Lopes,

$$
\begin{aligned}
& \text { as análises relativas às formas de vida social tornadas típicas das } \\
& \text { sociedades ocidentais contemporâneas adotam, para as nomear, ora } \\
& \text { o termo de modernidade tardia, ora o termo de segunda fase de } \\
& \text { modernidade, ora, ainda, o termo pós-modernidade. A distinção } \\
& \text { encerra um posicionamento sobre a própria modernidade: Haber- } \\
& \text { mas e Giddens, por exemplo, mantêm-se no registro da modernida- } \\
& \text { de, invocando que a sua realização plena ainda está para vir; outros, }
\end{aligned}
$$


como Rainier Zoll, assumem reservar o termo pós-modernidade para nomear uma sociedade que se imagina como um sistema que venceu a penúria dos alimentos, se desmilitarizou, humanizou a sua tecnologia e se caracteriza pela participação democrática do homem em níveis múltiplos. (LOPES, 2001, p. 25).

Ao se referir à "luta poderosa e dinâmica entre duas forças sociais imensas: a modernidade e a pós-modernidade", Hargreaves caracteriza a modernidade como:

uma condição social que é simultaneamente guiada e sustentada pelas crenças iluministas no progresso racional científico, no triunfo da tecnologia sobre a Natureza e na capacidade de controlar e melhorar a condição humana através da aplicação deste manancial de conhecimento e de saber científico e tecnológico especializado ao campo das reformas sociais (A. HARGREAVES, 1998, p. 9).

Para proceder a uma reflexão mais detalhada, este autor aponta quatro níveis de análise: o econômico, o político, o organizacional e o pessoal.

No nível econômico, considera Hargreaves (1998) que a modernidade marca a passagem do locus de trabalho da família, onde se fazia de tudo um pouco, para a fábrica, onde a especialização se extremiza, dando início ao processo de produção em série, característico do capitalismo monopolista ou do socialismo de Estado, como formas de aumentar a produtividade e a eficácia. Os processos de trabalho passam a ser altamente especializados, separando os gestores dos trabalhadores, a planificação da execução, o trabalho de pensar e de fazer. No nível político, associa a modernidade à consolidação do Estado Nação, enquanto força militar, e ao aparecimento do Estado Providência a regular a relação entre, por um lado, a educação e a segurança social e, por outro, a economia. Afirma que a centralização do poder, diretamente ligada às tomadas de decisão, e a aplicação de políticas econômicas Keynesianas, tornam o Estado mais forte e intervencionista, isto é, um Estado planificado que "tanto protege como vigia a população em redes cada vez mais amplas de regulação, de controle e de intervenção" (op. cit.: 30). No nível organizacional, estes princípios se refletem em pesadas máquinas burocráticas, fortemente hierarquizadas e segmentadas em divisões de competência técnica.

Finalmente, no nível pessoal, ele considera que a organização deste tipo de sistema e de ordem, se por um lado pode conferir algum sentido de identidade e pertença coletiva, por outro, também pode conduzir à alienação ditada pela impessoalidade racional.

A leitura desses princípios no plano concreto da escola moderna parece ser evidente pois determina que a aprendizagem deixe de ser natural e se faça num local próprio, com especialização de tarefas abarcando o maior número possível de crianças e jovens, de acordo com a lógica de produção em série, da qual resulta o ensino em massa. O modelo fabril marca a escola como símbolo da modernidade, pois "a idéia geral de reunir multidões de estudantes (matéria-prima) destinados a ser processados por professores (operários) numa escola central (fábrica) foi uma demonstração de gênio industrial." (Toffler, s.d., 393). 
As concepções modernas de Currículo estão efetivamente imbuídas da lógica de obsessão com a produtividade e eficácia, oriundas do mundo industrial. Em 1911, F. Taylor havia desenvolvido, para a indústria, uma teoria de gestão científica (The principles of Scientific Management) partindo da chamada job analysis, ou seja, da análise detalhada de gestos, seqüências e tempos necessários para a execução de tarefas. Para Freitas, "esse estudo servia de base para reorganizar os postos de trabalho, aumentando a produtividade, reduzindo os custos de produção e - claro - aumentando os lucros da empresa!" (FREITAS, 2000, p. 41). Ora, o modelo curricular proposto por Bobbitt visava transferir para a escola uma cultura de eficácia científica, uma vez que "a técnica de construção do currículo suportada por linhas científicas havia sido muito pouco desenvolvida." (BOBBITT, 1918, p. 15). Para ele, efetivamente, "a educação era um processo de moldagem, tanto quanto a manufatura de carris de aço.” (op. cit.: 259).

Para a análise que nos propomos realizar, reconhecemos inspirados por $\mathrm{B}$. Sousa Santos, que é necessária uma reflexão sobre a transição dos paradigmas societais e epistemológicos, dada a rapidez, a imprevisibilidade e a profundidade das transformações que ocorrem. Esse autor, referindo-se à transição paradigmática que a humanidade vive atualmente, considera-a "um período histórico e uma mentalidade", caracterizando-a da seguinte forma:

A transição paradigmática é $[\ldots]$ um ambiente de incerteza, de complexidade e de caos que se repercute nas estruturas e nas práticas sociais, nas instituições e nas ideologias, nas representações sociais e nas inteligibilidades, na vida vivida e na personalidade. (SOUSA SANTOS, 2000, p. 45).

Neste cenário, considerado, em tese, como o do fim da modernidade, existe uma consciência crescente da descontinuidade, da não-linearidade, da diferença, da necessidade do diálogo, da polifonia, da incerteza, da dúvida, da insegurança, do acaso, do desvio e da desordem. Reconhecendo-se que esteve na origem acidental do universo, a desordem passa a ser entendida mais como conjunto de informações complexas, no âmbito da auto-organização, do que como simples ausência de ordem (Morin, 1990).

Fazendo uso dos quatro níveis de análise de Hargreaves (1998), passemos, desde já, para a caracterização sumária do período enigmático em que vivemos. Deste modo, assistimos, ao nível econômico, ao declínio do sistema fabril, localizado na fábrica. Hoje já se torna difícil identificar o local exato de trabalho. As economias pós-modernas giram preferencialmente em volta da produção de bens mais pequenos, ao invés de bens maiores, de serviços, em lugar de manufaturas, de software, mais do que de hardware, de informação e imagens, mais do que de produtos tangíveis... Nesse quadro, a rentabilidade depende muito mais da antecipação e rápida reação às necessidades de mercado que se encontram em constante mutação. No nível político, e num contexto de uma economia em colapso, a que O'Connor chama de crise fiscal do Estado, se começa a questionar sobre a legitimidade da sua intervenção na regulação da vida econômica, com a determinação das taxas de juros, dos salários mínimos, dentre outros. De fato, com a dramática intensificação das práticas transnacionais, da internacionalização da economia, da migração e das redes de informação e comunicação, o Estado procura a sua auto renovação, dando início a um movimento de privatização de 
áreas que eram administradas por ele, indiscutivelmente, como as da saúde, segurança social e educação. Desponta assim um novo tipo de entidade não estatal para gerir a esfera pública: as organizações não-governamentais. Isso reflete necessariamente no nível organizacional, porque exige uma maior capacidade de resposta e uma flexibilidade tal que não dependa de pesadas máquinas burocráticas. A especialização de papéis dilui-se, estabelecendo-se hierarquias e fronteiras, através de tomadas de decisão descentralizadas, por estruturas cada vez mais horizontais.

Finalmente, no nível pessoal, observa-se que as relações sociais parecem estar cada vez menos confinadas a um tempo e a um espaço, com os indivíduos agrupando-se a partir de interesses afins, como acontece nas comunidades virtuais e nos grandes centros urbanos. A falta de permanência e de estabilidade na habitação, nos postos de trabalho, pode, por outro lado, originar crises nas relações interpessoais, uma vez que nem a tradição nem a obrigação constituem já fatores de coesão pessoal.

Portanto, construir um currículo para a formação de professores que obedeça a legislação vigente sem se deixar aprisionar pela rigidez por ela expressa, e ao mesmo tempo que represente a cultura gerada pelos contextos em que o processo ocorra, faz-se necessário embasá-lo numa concepção que permita uma flexibilidade para sua constante avaliação e reconstrução. Resta nos dizer que isto se configura em uma organização curricular que desenvolva uma linguagem expressa em desenhos que demonstre o movimento mantido através da pesquisa e da extensão, com elementos dinâmicos, que se transformam a partir de processos avaliativos acompanhando a dinâmica dos contextos sociais.

Ao se propor elementos para uma organização curricular, não se pretende definir um modelo, mas exatamente fugir dele, pois, ao aglutiná-los, buscou-se flexibilizar e dinamizar o processo de formação sem, no entanto desobedecer as Diretrizes Curriculares, apenas construindo uma linguagem contextualizada de construção de currículo.

Busca-se também romper com as dicotomias implícitas nas Diretrizes, quando se propõe um tema transversal e os eixos integradores que funcionarão a partir de objetivos, metodologias e formas de avaliação comuns, permitindo assim que o trabalho com áreas de conhecimento se transforme em arenas de discussão e inter-relação de práxis.

Entendemos, a práxis neste contexto como um movimento que vai da ação pedagógica para a teoria e que volta para a prática no sentido de transformar a realidade. Para Vázquez (1968), a práxis é atividade humana consciente que faz e refaz coisas, que transmuta uma matéria ou uma situação, é "[...] o ato ou conjunto de atos em virtude dos quais o sujeito ativo (agente) modifica uma matéria prima dada" (p. 245). Por isso, para compreender qualquer ação humana, é necessário conhecer a história e o contexto onde esta se realiza, pois a práxis é ao mesmo tempo subjetiva e coletiva, porta organicamente conhecimentos teóricos e práticos.

Neste contexto, faz-se necessário redefinir a proposta de formação e de construção curricular, bem como o papel da pesquisa e da extensão, que numa concep- 
ção formadora perdem o caráter de apêndice dos cursos, e tornam-se atividades que ganham um caráter processual ao serem integradas ao processo de ensino, através da construção e promoção de novos saberes que propiciarão a interconexão de práxis, que buscam a criação de condições para o desenvolvimento de novas práxis.

\section{Considerações finais}

Com as mudanças ocorridas no processo produtivo, grandes modificações perpassam, hoje, a sociedade. Considerando os interesses que permeiam esse processo, organismos internacionais ditam as normas, segundo as deliberações estabelecidas para cada área. As políticas públicas e a política educacional traduzem-nas e os textos legais thes conferem objetividade ao normatizarem o sistema educacional.

Os documentos oficiais apresentam propostas de formação condizentes com os interesses neoliberais e esses, na maioria das vezes, não são coerentes com o contexto socioeconômico, politico e cultural dos educadores, e nem com as reais necessidades impostas pela contemporaneidade para a formação do educador. Entendemos que é urgente formar uma concepção de formação pautada na perspectiva da emancipação e, para que isso aconteça são necessários estudos que explicitem os seus fundamentos. Para a concretização destes precisamos considerar a pertinência da articulação dos estudos desenvolvidos nos campos da formação do professor, do currículo e dos saberes docente, dada a complexidade de que se reveste a realidade educacional atual. Essa articulação se compreendida explicitada garantirá a construção de novas propostas curriculares de formação de professores.

Nesta perspectiva, é importante salientar que não há uma proposta que venha resolver a complexidade dos problemas enfrentados no terreno da formação docente. Por isso, o trabalho nesse campo só poderá avançar desde que as tentativas e alternativas de melhoria se abram para as críticas na busca da superação de seus limites e entraves. Um sério problema no campo educacional é a crença ou ilusão de que existe possibilidade de se encontrar uma resposta final para determinados problemas.

No que se refere à formação docente e sua profissionalização podemos afirmar que um currículo para a formação de professores demanda necessariamente uma reflexão sobre a formação e a prática docente. Em suma, entendemos o currículo da formação de professores como espaço de construção e reconstrução de conhecimento, cabendo, pois, ao docente participar de forma ativa nesse processo de construção. $\mathrm{O}$ desenvolvimento curricular está diretamente relacionado ao desenvolvimento da formação do professor no que se refere aos saberes e as práticas e suas relações.

\section{Referências}

APPLE, M. W. Aliança estratégica ou estratégia hegemônica? Conservadorismo entre os desfavorecidos. Educação e Sociedade. v. 24, n. 84. Campinas, set. 2003, p. 1019-1040. Disponível em: <http://www.cedes.unicamp.br>. Acesso em: 03 jan. 2008.

BRASIL. Lei no 9.394, Lei de Diretrizes e Bases da Educação Nacional de 20 de dezembro de 1996 publicada no Diário Oficial da União, 23 de dezembro de 1996 - Seção 1. 
BRASIL. CONSELHO NACIONAL DE EDUCAÇÃO; CONSELHO PLENO. Resolução CNE/CP 1, de 18 de fevereiro de 2002.

. Resolução CNE/CP 2 de 19 de fevereiro de 2002.

BOBBITT, F. The curriculum. New York: Houghton Miffin. 1918.

CURY, C. R. J. A educação básica no Brasil. Educação \& Sociedade, Campinas, CEDES, v. 23, n. 80, 2002. p. 169-201.

DIAS, R. E.; LOPES, A. C. Competências na Formação de Professores no Brasil: o que (não) há de novo. Educação \& Sociedade., Campinas, v. 24, n. 85, p. 1155-1177, dez. 2003. Disponível em: <http://www.cedes.unicamp.br>. Acesso em: 03 jan. 2008.

DOLY, A. Metacognição e medição na escola. In M. Grangeat (Coord.). A metacognição, um apoio ao trabalho dos alunos. Porto: Porto Editora, 1999. p. 17-60.

FREITAS, C.V. O currículo em debate: positivismo - pos modernismo - teoria-prática. Revista de Educação. IX (1), São Paulo, p. 39-52. 2000.

HARGREAVES, A. O ensino na sociedade do conhecimento: A educação na era da insegurança. Porto: Porto Editora. 2004.

Os professores em tempos de mudança: o trabalho e a cultura dos professores na idade pós-moderna. Alfragide: McGraw. Hill de Portugual. 1998.

JACKSON, P. Life in classrooms. New York: Holt, Rinehart e Winston. 1968.

LOPES, A. Libertar o desejo, resgatar a invenção. Lisboa: Instituto de Inovação Educação, 2001.

MORIN, E. Science avec conscience. Paris: Fayard, 1990.

PACHECO, J. Formação de professores: teoria e práxis. Braga: Universidade do Minho. 1995.

Políticas curriculares. Porto: Porto Editora, 2002.

PACHECO, J. A.; MORAES, M. C.; EVANGELISTA, M. O. (Orgs.). Formação de professores: perspectivas educacionais e curriculares. Porto: Porto Editora, 2003.

SANTOS, B. S. A crítica a razão indolente. São Paulo: Cortez, 2000.

SHULMAN, L. Knowledge and teaching: foundations of the new reform. Harvard Educational Review, 1987. p. 1-22.

SOUSA, J. M.; FINO, C. N. As TICs abrindo caminho a um novo paradigma educacional. In: SILVA, B.; ALMEIDA, L. (Orgs.). Actas do Congresso Galaico - Português de Psicopedagogia. Braga, Universidade do Minho. Portugual. 2003, pp. 371-381.

TARDIF, M. Saberes profissionais dos professores e conhecimentos universitários: elementos para uma epistemologia da prática profissional dos professores e suas conseqüências em relação à formação para o magistério. Revista Brasileira de Educação, n. 13, Campinas, Autores Associados, 2000.

TOFFLER, A. Choque do futuro. Lisboa: Livros do Brasil, sd.

TORRES, R. M. Melhorar a qualidade da educação básica: as estratégias do Banco Mundial. In: TOMASI, L.; WARDE, M.J.; HADDAD, S. (Org.). O Banco Mundial e as políticas educacionais. São Paulo: Cortez, 1996. p. 125-191.

VEIGA, I. P. A. et al. A Formação Continuada do Profissional da Educação. Caderno Linhas Críticas, Brasília: n. 3/4, p. 49-59, jul./jul., 1996.

VEIGA, I. P. A.; KAPUZINIAK, C.; ARAUJO, J. C. S. Docência: uma construção ético-profissional. Campinas: Papirus, 2005, v. 1.142p. 
VEIGA, I. P. A.; D’ÁVILA, C. (Orgs.). Profissão docente: novos sentidos, novas perspectivas. Campinas: Papirus, 2008.

YOUNG, M. The curriculum of future: from the "new sociology of education" to a critical theory of learning. London: Falmer Press. 1998.

WEBER, M. História geral da economia. São Paulo: Mestre Jou. 1968.

WHITTY, G.; POWER, S. Mercados educacionais e a comunidade. Educação \& Sociedade, Campinas, CEDES, v. 24, n. 84 (especial), 2003 p. 791-815.

\section{Notas}

${ }^{1}$ Grifo nosso.
${ }^{2}$ Grifo nosso.

* Professora doutora da Universidade de Brasília, Brasília, Distrito Federal, Brasil.

\section{Correspondência}

Liliane Campos Machado - Universidade de Brasília, Asa Norte, CEP: 70910-900, Brasília, Distrito Federal - Brasil.

E-mail:1cmpedagogia@yahoo.com.br

Recebido em 06 de agosto de 2015

Aprovado em 01 de março de 2016 